\section{Inferencia lógica del indicio: análisis de los procesos de simulación con base en el razonamiento probatorio del contexto}

Logical inference of evidence: analysis of simulation processes based on evidential reasoning of context
Sergio Andrés Caballero Palomino ${ }^{1}$

sergio.caballero@uniremington.edu.co

https://orcid.org/0000-0003-4715-8537

Johan Sebastián Lozano Parra²

sebaslp2308@gmail.com

https://orcid.org/0000-0002-3414-9984

Katerin Yulieth Cruz Cadena ${ }^{3}$

Katerin.cruz@uniremington.edu.co

https://orcid.org/0000-0003-2729-8030

Ludwing Castro Castañeda 4

lcastro@deleonlegal.com

https://orcid.org/0000-0001-6104-7652

Daniel Fabián Torres Bayona ${ }^{5}$

danfator@correo.uis.edu.co

https://orcid.org/0000-0003-1297-9482

\section{https://doi.org/10.22209/rhs.v9n2a01}

1 Docente de la Corporación Universitaria Remington Uniremington, Sede Bogotá. Corporación Universitaria de Ciencia y Desarrollo - Uniciencia, sede Bogotá.

2 Abogado y docente del Colectivo Nacional de Abogados.

3 Gerente General del Colectivo Nacional de Abogados. Docente de la Corporación Universitaria Remington Uniremington, Sede Bogotá.

4 Docente de la Corporación Universitaria Remington Uniremington, Sede Bogotá. Docente de la Universidad Republicana. Abogado y docente del Colectivo Nacional de Abogados.

5 Investigador externo, Corporación Universitaria Remington - Uniremington, Sede Bogotá. Abogado Senior y docente del Colectivo Nacional de Abogados. Profesor cátedra, Universidad Industrial de Santander.
Recibido: febrero 19 de 2021.

Aceptado: junio 25 de 2021.

\section{R e s u m e n}

El presente artículo esquematiza los resultados de una investigación cuyo objetivo general es analizar el estándar de la probabilidad prevalente en torno al indicio y al contexto como medios probatorios del proceso declarativo de simulación en materia del derecho civil colombiano. Por lo tanto, el aporte fundamental de esta investigación es priorizar los juicios lógicos-valorativos que realiza el juez en el análisis de la prueba indiciaria de contexto, frente al fallo judicial de un negocio jurídico simulado.

La pregunta problema por resolver, mediante una metodología básica jurídica, analítica, sistemática y hermenéutica es la siguiente: ¿La prueba de contexto configura un límite de valoración a los estándares de la prueba de indicio en las decisiones sobre los procesos de simulación? Sobre la cual se concluyó, finalmente, que, si bien no configura un límite de valoración, este sí permite el desarrollo del estándar de la probabilidad prevalente respecto de la simulación.

Palabras clave: decisión judicial; estándar probatorio; indicio; prueba de contexto; simulación. 


\section{Abstract}

This paper outlines the results of a research study aiming to analyse the prevailing standard of probability in relation to both evidence and context as means of proof in simulation proceedings in Colombian civil law. The fundamental contribution of this research study is to prioritise the logicalvaluative judgements made by the judge when analysing the context circumstantial evidence in court ruling on simulated legal transactions. The question to be addressed, by means of a basic legal, analytical, systematic and hermeneutic methodology, is the following: Does context evidence constitute a limit to the standards of circumstantial evidence in decisions on simulation proceedings? The paper concludes that, although it does not constitute a valuation limit, it does allow the development of the prevailing probability standard with respect to simulation.

Keywords: court ruling; standard of proof; circumstantial evidence; context evidence; simulation.

\section{Introducción}

\begin{abstract}
A partir de la Constitución Política de 1991, - Colombia, configuró una nueva forma de Estado denominada Estado social de derecho. Tal situación permitió, entre otras cuestiones, el ingreso de la convencionalidad como uno de sus principales estándares jurídicos. Así las cosas, es dable afirmar que las funciones del Estado se encuentran enmarcas por actuaciones que deben cumplir patrones internacionales, desde la rama ejecutiva, pasando por la legislativa y finalmente por la judicial. Es sobre esta última que, de manera más
\end{abstract}

concreta, indica Ferrer Mac-Gregor (2011) que se han creado figuras como la del control de convencionalidad difuso, la cual ha permitido el ingreso de instrumentos de regulación propios del Sistema Interamericano de Derechos Humanos, como lo son las reglas y la estructura de los diferentes medios probatorios que tales sistemas internacionales han venido desarrollando en su jurisprudencia, instrumentos que, de una forma u otra, el operador jurisdiccional de carácter nacional puede aplicar.

Como consecuencia de tal situación, el Juez Nacional, al igual que el Juez Interamericano, gozan de un margen de valoración probatorio que obedece a criterios establecidos por un esquema normativo, el cual se encuentra inmerso bajo la valoración de la sana crítica, sentido que permite desarrollar una decisión judicial imbuida bajo la racionalización de los medios de prueba solicitados para demostrar un hecho jurídicamente relevante; esto permite, en mayor medida, efectuar actuaciones lógicas, que se dirijan a obtener un mayor rango en los criterios de certeza sobre los procesos en concreto.

El Juez Interamericano no posee una codificación respecto de los medios probatorios a emplear en casos concretos, no obstante, tal situación lo ha llevado a estructurar sus propios medios y estándares probatorios por vía jurisprudencial, así como su libre valoración. Ejemplo de ello es la denominada prueba de «contexto» (Castañeda, 2011), la cual a todas luces se manifiesta y se encuentra positivizada dentro del marco del derecho procesal colombiano, bajo el título de la prueba de indicio; esto en la sección tercera, titulo único, capítulo VIII, artículo 240 a 242 del Código General del Proceso -en adelante CGP-, situación que le 
da un mayor plus al proceso, al poder entender el indicio como una manifestación propia del derecho convencional.

Ahora bien, la prueba indiciaria -sus límites, construcción, valoración- y sus estándares probatorios adquieren mayor preeminencia en procesos judiciales que versan sobre negocios jurídicos ocultos que, por lo tanto, ostentan una mayor complejidad al momento de ser probados (De Castro y Bravo, 1967); de ahí que, en un ejercicio de parangón entre distintos tipos de procesos, el que mayor rigor ofrece, al momento de ser valorado y probado por algún medio legal, sea el proceso de simulación.

Lo anterior adquiere un rango de lógica y veracidad al observarse que el origen de una decisión judicial sobre el proceso en comento tiene un trasfondo donde las partes de un negocio jurídico, en el cual se encontraban contempladas una serie de cláusulas, elevan su voluntad hacia una actuación diferente a la verdaderamente deseada y observable en la realidad; a su vez, un trasfondo en donde esas mismas partes han hecho todo lo posible por ocultar frente a terceros o frente a quienes se realizó el negocio, una serie de actos jurídicos, así como el material probatorio que dado el caso, cumpla con las formalidades legales necesarias; se obtiene así, un encumbramiento de las verdaderas intenciones mediante otro tipo de actuaciones (Albaladejo, G., 2005).

Por lo tanto, se advierte que el juez, al realizar un análisis valorativo conjunto de las diferentes pruebas que yacen en el expediente del proceso, debe, además de encontrar probada la simulación, trascender en el sentido de observar lo relativo a las exigencias legales que correspondan al negocio supuestamente simulado. Esto se erige como una muralla jurídica, la cual únicamente puede ser superada por la sujeción a unos estándares de la prueba indiciaria - respecto de la simulación- y la forma de valoración que ofrece la prueba de contexto -respecto a los hechos que dan cabida al negocio simulado-. En orden a lo anterior se plantea una pregunta problema que orienta el presente artículo, así como el objeto de investigación, que está encaminado a ahondar sobre los estándares de la prueba indiciaria y sus similitudes a la prueba de contexto, frente al proceso civil de simulación. Entonces: ¿La prueba de contexto configura un límite de valoración a los estándares de la prueba de indicio en las decisiones sobre los procesos de simulación?

Pregunta que se responde por medio de una metodología básica jurídica que estudia las fuentes jurídicas y jurisprudenciales pertenecientes a la temática del indicio y la prueba de contexto. De su lado tiene el carácter analítico, sistemático y hermenéutico en la medida que se acude a razonamientos jurídicos de índole probatorio, así como estudios de inferencia lógica de los componentes del indicio.

Es así que el artículo busca hacer aclaraciones de tipo conceptual y hermenéutico, que versen sobre el estándar probatorio del indicio en las decisiones judiciales sobre el proceso de simulación, partiendo de la yuxtaposición que representa la prueba de contexto como medio de valoración probatoria al estándar denominado "más allá de toda probabilidad». En tal sentido, se trazaron tres objetivos que permiten estructurar el contenido material y formal del escrito en los siguientes términos: el primero se encamina a establecer un prístino análisis acerca de la pertinencia de la prueba indiciaria para el proceso de simulación y cómo esta obtiene una base de nivel convencional por medio de las características propias 
y similares a la prueba de contexto. El segundo indaga acerca de los estándares probatorios de la prueba indiciaria, respecto a la influencia de esta en la toma de decisiones por parte del operador jurisdiccional, desde una perspectiva crítica del derecho y, finalmente, en el tercero se hace un bosquejo de la operatividad de la prueba de indicio dentro del análisis lógico de una decisión judicial sobre el proceso de simulación, como un tópico.

\section{La prueba de indicio y contexto en el proceso} de simulación

Uno de los principales elementos que constituye un negocio jurídico, el cual es en sí mismo un pilar que sostiene el derecho como ciencia, es la voluntad. Esta última, entendida como una posición, la cual le permite a un sujeto pasivo o activo llevar a cabo una actuación destinada a exteriorizar o dotar de consecuencias jurídicas a su entorno y a la sociedad. Es por ello que se entienda la voluntad no como una simple declaratoria de partes, puesto que, cuando esta entra en conflicto con la voluntad es esta la que debe prevalecer, toda vez que una declaración es una mera apariencia de voluntad (Savigny, 1879).

Es por ello que el reflejo de una voluntad sea la expresión de un negocio jurídico, el cual es la demostración de dos o más partes. No obstante, si bien esta es la regla general, existen ocasiones donde la voluntad dentro de un negocio jurídico no es representada de manera trasparente en la exteriorización del derecho, sino por lo contrario quiebra deliberadamente este equilibrio frente a un tercero, y es aquí donde nace la figura jurídica de la simulación y su consecuente acción (Acosta, 2010).

En efecto, tal situación de rango complejo y oscuro no le ha permitido a la simulación encontrar un marcado esquema demostrativo, toda vez que, tal y como se ha venido indicando, no basta únicamente con probar la existencia del negocio jurídico simulado, sino que se tienen que probar los hechos que dan cabida a tal simulación; Por ello en las decisiones judiciales sobre este tipo de procesos en su gran mayoría, la parte resolutiva, termina con la declaratoria de una nulidad. Aspecto que en muchas ocasiones no pertenece a las verdaderas pretensiones de las partes.

Es sobre estas inconsistencias que la prueba de contexto permite evidenciar una serie de sucesos ajenos a las voluntades de las partes en los negocios jurídicos, esto frente a los hechos objeto de la simulación. La prueba indiciaria como inferencia lógica permite entonces demostrar con mayor probabilidad -estándar probatorio- un hecho que denote la existencia de una simulación sobre un negocio jurídico determinado. Cuestionamiento, que, si bien puede acarrear amplias similitudes, le permite al juez decidir con mayor seguridad y de manera más específica.

\section{La acción de simulación}

\section{y la prueba indiciaria}

La figura jurídica de simulación ubicada en el artículo 1766 del Código Civil -Ley 57 de 1887-, al igual que cualquier otro negocio jurídico, goza de prerrogativas principialísticas como la presunción de veracidad, lo cual se traduce en que tal negocio jurídico se entiende 
legítimo y auténtico hasta que no se demuestre y pruebe lo contrario. En sentido probatorio, respecto a la carga dinámica, quien se disponga a demostrar un hecho en concreto, mediante la utilización de algún medio probatorio, y en este caso propiamente mediante el indicio, más allá de toda probabilidad, debe orientar sus esfuerzos y su discurso a desvirtuar esa presunción de veracidad de la que goza negocio jurídico cuestionado. Siendo así, que quien alegue la existencia de una simulación debe encaminar todo el material probatorio en el sentido de romper con un atributo que ostenta un nivel constitucional. Asunto que, en contrario, al fallar en la demostración indiciaria, estaría fortaleciendo la ilegalidad e ilegitimidad de un negocio jurídico que se hizo público mediante las apariencias. Ello se interpreta conforme al aforismo latino «In dubio benigna interpretatio adhiben da est, tu magis negotium valet quam pereat» (Corte Suprema de Justicia, Sala Civil, S3390, 1992).

\section{Nociones jurisprudenciales de la acción de simulación}

En efecto, para la jurisprudencia de la Corte Suprema de Justicia, la simulación constituye por contera un negocio jurídico, cuya estructura central está conformada por «un designio común, convergente y unitario» (Corte Suprema de Justicia, Sala Civil, SC077, 2008) donde las conductas tienen apariencia de realidad y al ser aparente la verdad está reservada de manera única y prevalente para las partes.

Como consecuencia de lo anterior, el alto tribunal ha expresado que existen dos formas de abordar la simulación una absoluta y otra relativa. Respecto de la primera esta es inter partes y la realidad expresa la inexistencia o ausencia total del acto o situación que se busca declarar como aparente al tenor de un supuesto acuerdo. En caso de la segunda, expresa que las actuaciones fueron realizadas de buena fe de manera que el negocio que se celebra está conforme al contenido jurídico de lo actuado y acordado con las partes. Por ello, los negocios jurídicos tendrían apariencia de verdaderos.

Teniendo de presente lo anterior la sentencia de la Corte Suprema de Justicia 6411 de 2002 expresa que cuando se habla de simulación esta no está encaminada a demostrar la existencia de un vicio dentro de un negocio jurídico «(...) sino a una forma especial de concertarlos conforme a la cual las partes consiente y deliberadamente disfrazan la voluntad real (...)» con una abiertamente pre acordada. Por ello que el indicio sea la prueba idónea para demostrar esta situación jurídica.

\section{Condiciones o requisitos para la simulación}

Las condiciones para que un negocio sea considerado simulado y posteriormente declarado por vía de fallo jurisdiccional son las decantadas en la sentencia C-071 de 2004, estas son tres (3). La primera que las partes hubiesen celebrado entre ellas un contrato en la realidad; la segunda que con posterioridad a la realidad del contrato o acto se celebre uno aparente -sobre este cabe indicar que se debe tener certeza del tiempo en que se celebró el acto simulado puesto que el acto que fue simulado revoca los actos anteriores a los convenidos-, en tercer momento, debe existir un acto eventualmente secreto donde su existencia se vislumbra por el acto supuestamente aparente. De la Morandiere (1966) expresa que la simulación a razón de las situaciones que la condicionan puede recaer sobre el objeto contractual, la causal o las personas que lo celebra.

La idoneidad del indicio 
como medio de prueba

En orden a lo indicado al inicio del presente capitulo, el fin mismo de obtener una decisión judicial, respecto a un proceso de simulación, es demostrar y probar la voluntad de una o de ambas partes, de ocultar la verdad, $y$, en consecuencia, la presencia de mala fe en la realización de cierto negocio jurídico; en la generalidad, este actuar no tiene mayor intención que la de defraudar a terceros que pudiesen tener un interés de persecución del bien objeto del negocio simulado. En palabras de Antonio Rocha Alvira, en materia de simulación, se tiene que: "hay que demostrar o probar aquella voluntad privada que es la que contiene la verdadera de las partes (...)» (Rocha, A., 1967, p. 437).

Este precepto se encuentra fortificado por la sentencia 7145 del 19 de mayo de 2004 de la Corte Suprema de Justicia, la cual establece una serie de etapas, respecto a la forma en que al operador jurisdiccional le corresponde analizar la existencia de una posible simulación, señalando que debe tener en cuenta lo siguiente:

a. La existencia del negocio jurídico -ya sea este un acuerdo, un contrato, una escritura, etc.-.

b. La legitimidad en la causa del actor que promovió el proceso respecto de la acción de simulación -es decir, un interés y finalidad que mueva la voluntad de este-

c. Los medios de prueba pertinentes para establecer con mayor probabilidad los hechos de la simulación.

Conviene entonces mencionar que si bien el CGP establece como principio el de la libertad probatoria, esto no significa que no deba existir un estándar probatorio que se debe alcanzar en materia de simulación; por lo tanto, el operador jurisdiccional en lo que concierne al punto «c» anteriormente comentado, es decir, respecto de los medios probatorios que se le aporten o soliciten con la demanda, debe indagar en el contexto de la situación de las partes y en los indicios que lo encaminen como única vía a obtener una mayor certeza; así como a emitir una decisión positiva a la parte actora que estimuló el proceso, o bien, positiva respecto a quien excepcionó la inexistencia de la simulación dentro de dicho proceso civil.

Lo anterior se debe en gran medida a lo esbozado por la Corte Suprema de Justicia en la sentencia 5016 del 17 de noviembre de 1998, al indicar que la prueba indiciaria suele satisfacer en amplia escala a la carga dinámica de la prueba, lo cual busca demostrar en el sentido extenso, que los hechos en los que se funda la pretensión de declarar la simulación sobre un negocio jurídico, difícilmente se podrían demostrar con otro medio probatorio que no se encuentre rodeado de ilegalidades, ya sea este un medio directo de prueba. Así mismo, dicho tribunal ha señalado que el indicio suele ser la única forma de demostrar una simulación cuando en los procesos no exista un documento escrito en manos del accionante que le permita, de manera concreta, recrear el contexto de una situación. En otros términos, se tiene que «(...) Y es que si la prueba se dificulta cuando las partes (...) despliegan su mayor esfuerzo por destruir todo rastro que permita revelar la realidad, lo que resulta virtualmente imposible es demostrar directamente el móvil (...) concreto, [y] racional que impulsa la simulación (...)» (Acosta, 2010, p. 394).

Es por ello que el indicio resulta ser un medio probatorio con una categoría especial y superior, que se reviste como una prueba de 
carácter indirecto, contemplada concretamente en el artículo 242 del CGP, en donde se apreciará de manera entrelazada a las demás pruebas que obren dentro del expediente del proceso; es en este punto, donde el juez va a entrar a considerar la mayor probabilidad de un hecho cierto con base en la gravedad, concordancia y convergencia del mismo.

\section{La inferencia lógica del indicio y el contexto}

La Corte Suprema de Justicia en decisión del 4 de septiembre de 2006, mediante sentencia 5826 señala que el indicio -y por ende el contexto- son inferencias lógicas que por un lado permiten determinar un hecho indicador y por otro un hecho desconocido, en aras a entablar una conclusión. La doctrina ha explicado estos medios de prueba como silogismos que realiza el juez para poder llegar a una decisión judicial que cumpla el estándar «más allá de toda probabilidad razonable» (Vallejo Montoya et al., 2012). Tal convicción, que realiza el juez se puede expresar de la siguiente manera:

La premisa mayor, en el caso del proceso de simulación, debe ser un hecho indicador que se encuentre dentro del libelo genitor del proceso, creando consigo a su vez una presunción relativa -cuestión que resulta propicia para entablar el contexto de la situación-. Estas eventualidades son cuestionadas por el juez mediante aplicación de las máximas de la experiencia y la sana crítica a cada uno de los medios que son objeto de valoración probatoria (Bentham, 1979).

La premisa menor es en sí misma una comprobación hacia los hechos del negocio jurídico y de la simulación, creando ahora lo que es, no una presunción relativa, sino una circunstancia indicativa. Tal fin se lleva a cabo comprobando mediante otros medios de prueba una situación de contexto específica.

La conclusión, también medio de prueba propiamente dicho, es obtenible a partir de la premisa mayor (presunción relativa pero cierta) y la premisa menor (circunstancia indicativa pero abstracta); es en este instante, en donde los datos se concretan en la mente del sujeto jurisdiccional, el cual mediante las operaciones mentales denominadas presunciones (Mittermaier, 1979) puede arrojar un contexto de la situación de las partes del proceso y por lo tanto, decidir qué hecho tiene mayor probabilidad de ser cierto.

\section{Razonamiento probatorio de la prueba indiciaria y de contexto}

Si bien la Corte Suprema de Justicia de un modo u otro ha encaminado su jurisprudencia a señalar de manera indirecta que los indicios son razonamientos lógicos -silogismos-, esta no es la única forma de llegar a la misma conclusión en lo que se refiere al proceso de simulación. La doctrina, ha concluido que existen dos razonamientos que permiten la funcionalidad de la prueba indiciaria y, por ende, de la prueba de contexto:

\section{La función heurística}

Se puede hablar de manera clara y directa de una función heurística como proceso de razonamiento lógico cuando la prueba indiciaria, en este caso la de contexto, accede a la formulación de hipótesis con base en un hecho, el cual permitirá el descubrimiento provisional de la situación actual del negocio jurídico puesto en duda por la simulación del mismo (Taruffo, 2011). A tal acontecer, se le denomina 
contexto de descubrimiento (Zavaleta Rodríguez, 2018).

\section{La función probatoria}

De esta manera, se vislumbra que la práctica más clásica y generalizada por parte del operador jurisdiccional, se basa en encaminar la prueba indiciaria, del hecho indicativo a la conclusión por medio de los hechos probados. A esta situación se le ha llamado el contexto de justificación (Zavaleta Rodríguez, 2018), en el entendido de que dimensiona el razonamiento probatorio de una hipótesis a una prueba, circunstancia que en la función heurística es contraria, pero igualmente valida al encaminar la prueba hacia una posible hipótesis.

Ambas situaciones no implican, de ninguna manera, distinciones hacia el proceso de simulación, dado que permite desarrollar un marco en el cual el juez tiene la posibilidad de llegar a una misma decisión, mediante diferentes caminos, dando cumplimiento consigo al estándar valorativo de más allá de toda probabilidad. Al llegar a este punto se puede afirmar que: «(...) el proceso de descubrimiento de una hipótesis no es estrictamente independiente del proceso para su "validación", pues ambos forman parte de una misma metodología inductiva» (Gascón, 2014).

\section{El contexto: de la convencionalidad a la nacionalidad del indicio}

Tal y como se proyectó en el anterior numeral, las particularidades del indicio, desde las formas lógicas de comprender su validación, permiten la recreación de distintas manifestaciones del contexto de las partes como una prueba, ya sea este de descubrimiento o de justificación. Cabe mencionar que tales circunstancias de carácter doctrinal se ven recreadas en el proceso judicial al momento de observarse bajo la luz del principio de libertad probatoria, del cual se sirve cada abogado al momento de encaminar los hechos y de aportar y solicitar pruebas dirigidas a la demostración de un falso negocio jurídico.

Empero, el contexto es un medio probatorio propio de la Corte Interamericana de Derechos Humanos, el cual ha sido instituido para la valoracióndecasos detalantenacionalytrasnacional, este debe ser entendido en este caso como «lascircunstanciasquerodeanelhechoyelcaso en concreto» (Castañeda, 2011, p. 115), siendo necesario y jurídicamente viable que cada juez no solo analice desde una perspectiva lógica el hecho de la simulación, sino que cree un puente de relación del contexto con la prueba indiciaria. En consecuencia, se abre una vía para analizar una posible violación, no de hechos internacionalmenteilícitos, sinodehechosnacionalmente ilícitos o ilegales, es decir, se estaría partiendo de hechos probablemente conocidos a hechos ciertamente desconocidos.

De acuerdo con lo anterior, el contexto tiene como virtud representar y demostrar hechos concretos y pasados respecto a la violación de las voluntades de las partes en un negocio jurídico - llámese contrato, acuerdo, entre otros-. Esto le permite al juez, mediante una inducción y deducción, establecer la existencia o no de una simulación. La prueba de contexto, por lo tanto, no es sino el hecho indicativo de la prueba indiciaria; esto a su vez permite corroborar todo valor probatorio más allá de toda probabilidad de la existencia o inexistencia de un hecho simulado.

Acudiendo a criterios hermenéuticos propios 
de la interpretación jurídica, la jurisprudencia de la Corte Interamericana, respecto del contexto, ha señalado la existencia de dos clasificaciones: La primera, denominada como «general», la cual le permite al juez conocer de una situación relacionada con la vulneración de derechos humanos, que aplicado al caso del proceso de simulación, se tiene que el juez buscará ahondar en la situación respecto a la violación de normas de tipo sustancial encontradas en el marco del derecho civil y comercial, corroborando la existencia de patrones de nivel sistemático que le permitan verificar un suceso con el mayor rango de probabilidad y evitar por lo tanto contrarrestar la incertidumbre jurídica que deviene de la existencia de un negocio camuflado de legal. El segundo de tipo "especifico o concreto», que se refiere, por una parte, a las circunstancias que rodean la situación. En el caso del contexto interamericano, este hace referencia a los conflictos; en materia de simulación, hace referencia a los demás procesos o negocios jurídicos que circulan, así como hechos objeto de conocimiento de la parte accionante (Castañeda, 2011, p. 119).

\section{El estándar valorativo más}

\section{allá de toda probabilidad en la prueba indiciaria}

Partiendo de la concepción que establece el estándar probatorio de más allá de toda probabilidad prevalente, el cual es comprendido como la preeminencia que ostenta un medio probatorio frente a otro para hacer más o menos probable un determinado hecho (Taruffo, 2009), es viable afirmar que el operador jurisdiccional al momento de realizar su decisión, se encuentra llamado a analizar los hechos jurídicamente relevantes, conforme a los medios de prueba regular y oportunamente aportados al proceso, y a establecer a manera de criterio, a cuáles eventualmente se les otorga mayor grado de certeza, a partir de los juicios de valoración de la sana crítica.

Tal y como se previó en el numeral 1.3 sobre las maneras como el juez, de forma razonable en el proceso de simulación, puede entablar una hipótesis con base en las pruebas. Tal estándar corrobora este medio, puesto que el criterio de "probabilidad prevalente» permite la posibilidad de escoger qué formula probatoria, basada en el indicio, se ajusta mayormente a derecho y a la razón. Es menester que tal probabilidad supere con creces todo grado de razonabilidad, lo cual le permita dar certeza a un hecho.

En consonancia con el artículo titulado «Conocimiento científico y estándares de prueba judicial», de Michelle Taruffo (2005), traducido por Carbonell \& Salazar, se pueden esbozar de manera concreta, la existencia de cuatro premisas, que, además de las ya establecidas en el aparte anterior, deben tenerse en cuenta al momento de proferirse un fallo que verse sobre el negocio jurídico presuntamente simulado. Estas son:

i) La decisión a la que llegó el juez respecto de la simulación del proceso, debe en cierta manera corresponder a la elección de varias hipótesis, que en concreto permitan la reconstrucción de cada uno de los hechos que originaron no solo la simulación, sino el negocio jurídico originalmente efectuado por las partes o bien la inexistencia de negocio alguno.

ii) Que la decisión respecto a cada uno de los 
hechos y pretensiones se encuentre fundamentada en criterios de racionalidad, propios del medio de prueba del indicio y el contexto.

iii) Que el juez considere verdadera la hipótesis que escogió sobre los hechos que fueron demostrados y probados dentro del proceso de simulación, circunstancia que le permita justificar de mejor manera el por qué escogió cierta hipótesis y el por qué otras no se encontraban fundadas, no obstante, se encontraran encaminadas sobre ciertos indicios.

iv) Respecto a la libertad probatoria, el juez debe entender que, en el caso del proceso de simulación, debido a la dificultad que éste presenta, es necesario recurrir al indicio como prueba maestra, puesto que este estándar probatorio no busca concretar un grado de certeza sino un grado de confirmación en la veracidad de los hechos mediante las pruebas. De aquí que esta última premisa, pretenda concretar cuáles son, dentro de la simulación, los elementos que confirman la existencia de la misma.

\section{El problema de la probabilidad prevalente en el proceso de simulación}

Se puede afirmar, al igual que indica Puentes (2019), que un estándar probatorio es un criterio o una serie de razones por las cuales se permite concluir de manera acertada un hecho o una situación; en efecto, la probabilidad prevalente permite de manera ordenada, concluir un proceso de forma afirmativa a la parte demandante o a la demandada, esto es: «(...) cuando la relación entre la prueba o las premisas justifican la aceptación de una conclusión» (Laudan, 2005, p. 104).

Noobstante,talaseveraciónpermiteentablaruna serie de problemas referidos a la aceptación de una conclusión determinada, pues, si bien existenpatronesyrazonamientoslógicosrespectoa los hechos, y estos son corroborados mediante el contexto indiciario, este medio probatorio no goza de un estándar claro que permita ahondar más allá de lo debatido dentro del proceso de simulación, ni permite ratificar comportamientos indebidos respecto del derecho -es decir maniobras engañosas que puedan acarrearuna serie de investigaciones de tipo penal-. Es así como se emprende una disputa dirigida simplementeadeclararunasimulación, perosinaportar soluciones adecuadas para la realización de los negociosjurídicos deseadosdemaneraapropiada,cuestiónquelosmismosindiciosyelcontexto de la situación prevén como medio, pero no fin (Puentes, 2019, p. 124).

Es importante señalar que, en el campo de la simulación, esto se observa con mayor asiduidad, puesto que requiere no solo la generación de indicios y contextos, al ser estos el principal medio probatorio; sino que también trae consigo una multiplicidad de decisiones que, en gran medida, pueden ser todas certeras como todas falsas. Estas condiciones, si bien parecen paradigmáticas, no permitirían el cumplimiento del estándar de la prueba de la probabilidad prevalente, toda vez que se pone en situación de disyuntiva al operador jurisdiccional, porque la hipótesis basada en un hecho no depende exclusivamente de un único indicio $3 / 4$ tarifa legal ya superada $3 / 4$, sino de una multiplicidad de indicios con potencial de otorgarle mayor o menor veracidad al mismo. Entonces, dependiendo del modo en que el juez los interprete dentro de su marco organización de ideas, no solo basta un indicio o un 
contexto, así como un estándar, sino que todo debe conectarse bajo los juicios valorativos de la sana crítica y las reglas de la experiencia.

\section{Crítica constructiva al modelo} de estándar indiciario

El problema de la probabilidad prevalente dentro de una simulación de negocio jurídico encuentra su justificación en la forma que se realizan los juicios valorativos explicados en títulos anteriores; esto se puede analizar en cuatro grandes momentos. El primero, donde el problema de la simulación es el juicio o proceso, en el cual un juez debe analizar varios hechos, hipótesis y pretensiones, y lo hace sirviéndose de la creación y valoración de indicios; el conflicto no surge de la elección de las diferentes alternativas acertadas, sino que se da al momento de resolver, con indicios y contextos, todas las incertezas generadas de los hechos, y con ello, poder delimitar de mejor manera su análisis probatorio; esto es el resultado de afirmar que cada hecho puede ser verdadero y falso al mismo tiempo, conforme a la interpretación que no solo el juez realice, sino en como las partes lo demuestren, puesto que un hecho tiene una infinidad de formas de señalarse verdadero, así como de demostrarse falso mediante los mismos medios (Orayen \& Moretti, 1986). El segundo momento, depende de cada juez, previo a la realización de los razonamientos lógicos de los indicios y contexto, al aplicar a elección propia, un segundo o tercer análisis deductivo, que le permita concluir no solo respecto de los hechos, sino conforme a derecho. Como tercer momento cabe mencionar que respecto a la simulación solo se puede hablar de verdades relativas, toda vez que los indicios por sí solos no le permiten al juez asumir una verdad, sino como lo dice el estándar, asumir una probabilidad.
Finalmente, como último y cuarto momento, el juez debe comprender que este estándar se denomina probabilidad prevalente, por ofrecer diferentes situaciones ya sean bajas, medias o altas; es decir, no todo proceso arrojará un indicio que permita mostrar, con mayor rango de probabilidad, la existencia de una simulación, basta con entablar un rango que sea razonable para el contexto y, por ende, la futura decisión judicial.

\section{El indicio en la decisión judicial del proceso de simulación}

La Sala de Casación Civil y Agraria de la Corte Suprema de Justicia ha sido clara respecto de las decisiones judiciales que puedan ser emitidas conforme a un proceso de simulación y cómo estas dependen, no solo de los medios probatorios y los juicios valorativos que realice el operador jurisdiccional, sino que resulta importante la especie o tipo de simulación que sea declarada, en el caso del derecho civil colombiano existen dos tipos:

La primera, denominada simulación absoluta, es declarada siempre y cuando los indicios permitan al juez con un mayor rango de probabilidad determinar que el negocio jurídico que se realizó de manera ineludible debe salir del mundo del derecho, al observarse de manera verídica que tal negocio nunca existió. La segunda, la simulación relativa, la Corte Suprema de Justicia, el 6 de mayo de 2009, en sentencia 2002, ha presupuestado este tipo de declaratorias cuando con un mayor rango de probabilidad prevalente se pueda deducir la existencia de un negocio jurídico, pero este 
es diferente del simulado. De tal forma que el juez acudiendo a razonamientos lógicos señale qué tipo de hechos prueban la simulación, qué tipo de hechos prueban la existencia del verdadero negocio jurídico celebrado.

Esto último es de suma importancia para el derecho, toda vez que obliga al juez a determinar por circunstancias propias del derecho, puesto que existen negocios jurídicos que requieren de una serie de prerrogativas las cuales, al no cumplirse del todo, le restan fuerza al negocio jurídico deseado, como lo son los casos de la simulación contractual y de la donación; en la más reciente sentencia de la Corte Suprema de Justicia, fallo 2007 de 2019, se estableció como regla general que en los casos que se alegue la simulación, bastará con la prueba indiciaria para demostrarla. No obstante, si el proceso versa sobre la simulación de una donación, será necesario acudir a los criterios del artículo 1458 del Código Civil. Caso en contrario, se le restaría fuerza al negocio jurídico y con un mayor rango de probabilidad se pueda declarar una simulación de tipo relativo. Así mismo, en materia contractual, para evitar una simulación relativa, debe dentro del proceso evidenciarse que las partes del negocio jurídico tienen la potestad de justificar el objeto materia del contrato, así como de definir la perentoriedad de los requisitos propios del negocio jurídico.

Posterior a la declaratoria de uno de estos dos tipos de simulación, el juez ordenará que se le restituya los derechos, de ser el caso, a las personas afectadas de manera negativa, situación que, si bien es deducible a partir de las pretensiones de la demanda, es necesario acudir nuevamente a los indicios establecidos como medios de prueba para reforzar tal petición y brindarle seguridad jurídica a la decisión.
Para este caso se ejemplifica una situación establecida en el año 2006 por la Corte Suprema de Justicia, en materia de restitución, donde el Alto Tribunal habiendo declarado la simulación aparente ordena la restitución del inmueble en el estado que fue entregado y en caso de que esto hubiera sido imposible, se restituyan derechos no como propietario, sino como acreedor defraudado, en razón de la simulación -situación que solo es posible previos razonamientos lógicos acerca del mayor porcentaje de probabilidad verídica de los hechos de la demanda-.

No obstante a lo anterior, los indicios también pueden encaminar a declarar una situación positiva sobre un tercero, así lo sustentó la Corte Constitucional mediante sentencia C-071 que buscó la declaración de inconstitucionalidad sobre los preceptos que desarrollan la acción civil de simulación; en esta, la Corte Constitucional señala que la eficacia de los medios probatorios de los indicios pueden determinar, según el proceso, los efectos de una declaratoria no únicamente en contra de terceros, sino que a favor de estos.

\section{Conclusiones}

En torno a lo relacionado con la teoría de la simulación en el derecho colombiano, construida a partir del artículo 1766 del Código Civil, es posible entrever que se cimienta en una intención oscura desplegada por las partes que conforman un negocio jurídico, ya sea de fingir la existencia de cierto acto, o de hacerlo parecer y atribuirle características de otro tipo de negocio, con el objetivo final de producir un perjuicio a un tercero, no necesariamente determinado, que pudiese llegar a tener un interés en el patrimonio que es objeto de la 
controversia. En ese orden de ideas, a manera de colofón se puede indicar lo siguiente:

- Nacen diversas dificultades a nivel probatorio para la acción judicial que se emprende en aras de obtener la declaratoria de simulación, bien sea del orden relativo o absoluto, porque en la generalidad, los actores han encaminado su actuar a ocultar lo mejor posible dicha simulación; tal evento arroja un negocio jurídico que, como todos los demás, goza de una presunción de autenticidad de carácter constitucional, que es finalmente la que debe ser desvirtuada por el accionante.

- La prueba indiciaria se ha venido consolidando como un instrumento probatorio que arroja luces ante la carencia de medios directos que sirvan para determinar la existencia de una simulación en un caso concreto. No obstante, al analizar las condiciones de valoración de la prueba indiciaria, se advierte la inexistencia de un límite o estándar que sirva al operador judicial como una certeza más allá de toda probabilidad, para que, en tal sentido, se profiera una declaratoria de simulación, o, por el contrario, una sentencia que declare la prosperidad de las excepciones elevadas por el accionado.

- Ante las falencias en la valoración a la prueba indiciaria -como única base en la decisión judicial sobre la simulación-, brota la necesidad de entablar estándares que ofrezcan seguridad jurídica tanto al operador jurisdiccional, como a los actores dentro de un proceso. Es la prueba de contexto, aplicada al proceso de simulación y articulada con la prueba indiciaria, la que ofrecería un albor viable en el camino de creación de estándares que resguarden los fallos declarativos en procesos de este talante.

- Se tiene que el contexto, como medio probatorio construido por vía jurisprudencial por la Corte Interamericana de Derechos Humanos, y que por lo tanto es parte del ordenamiento colombiano en uso del control difuso de convencionalidad, configura un límite de valoración a los estándares de prueba de indicio en las decisiones sobre procesos de simulación. En otros términos, este medio probatorio puede ingresar al presente proceso a fortalecer la prueba indiciaria, en el sentido de i) crear un estándar en la valoración de las diversas pruebas, enfocado a la construcción del indicio, y ii) abrir túneles que permiten al juez decidir sobre mayores elementos de certeza.

- En suma, la propuesta de inclusión de los elementos propios de la prueba de contexto al proceso de simulación y a la valoración de la prueba indiciaria se ve amparada por dos grandes elementos que permiten concluir su pertinencia, a saber: i) el control de convencionalidad difuso que consiente la entrada de instituciones y elementos del derecho internacional, al ordenamiento interno; prerrogativa contenida en el artículo 93 constitucional. Por otro lado, ii) el principio de libertad probatoria, propia del actual CGP y los nuevos modelos de valoración y construcción de las pruebas en conjunto, en este caso, la prueba indiciaria. De esta manera, se consolidan lineamientos que vigorizan la función judicial y la seguridad jurídica en lo que tiene ver con el proceso de simulación en concreto, circunstancia que hace de Colombia un país pionero en la inclusión real de elementos probatorios de orden convencional.

- En torno a la crítica que ofrece el artículo en relación al modelo de estándar indiciario de que trata el segundo aparte, es dable 
concluir que existe una dicotomía consistente en que un hecho concreto puede tomarse como cierto o falso al mismo tiempo, partiendo de la utilización de un mismo medio probatorio. De ahí la trascendencia que guarda la función judicial, al momento de adoptar una hipótesis u otra, constituyendo el manejo del contexto, una circunstancia determinante para la decisión judicial sobre la simulación, y una tercera vía para la construcción de una motivación válida.

- Es así que, no obstante, existan métodos como el silogismo y la teoría heurística, el estándar actual denominado más allá de una toda probabilidad prevalente, posee falencias que desembocan en grados de certeza muy bajos en lo relativo al proceso de simulación y la valoración de la prueba indiciaria.

- En orden a lo señalado en el tercer apartado, se tiene que, en cuanto al indicio construido en el curso de un proceso de simulación, deben observarse los dos tipos de declaratoria de simulación que se presentan; de acuerdo con lo señalado por la Sala Civil de la Corte Suprema de Justicia, se habla por un lado de simulación absoluta y por otro de simulación relativa, produciendo efectos en consecuencia de ello.

- En la simulación absoluta, el juez debe establecer en la decisión judicial, con el mayor grado de probabilidad, que el negocio jurídico analizado jamás existió en la realidad de los actores. En el caso de la relativa, el operador debe establecer que, bajo un negocio jurídico aparente, elevado por los actores del mismo, existe otro distinto. En ambos debe el juez procurar el amparo de los derechos que han sido vulnerados a los terceros por medio del negocio simulado, también partiendo de los indicios creados y, en consecuencia, del contexto observado y válidamente constituido.

\section{Referencias}

Acosta-Madiedo, C. D. (2010). Simulación de actos jurídicos: Teoría, acción y los efectos de su declaración. Revista de Derecho, (34), 377-409.

Albaladejo García, M. (2005). La simulación. Editorial Edisofer.

Bentham, J. (1979). Tratado de las pruebas judiciales. Ediciones Jurídicas Europa - América. Castañeda Quintana, L. F. (2011). El contexto como materialización de la prueba indiciaria en la corte interamericana de derechos humanos. Revista Nueva Época, (37), 99-124. http://bit.ly/3dMJ0L5 Colombia, Corte Constitucional, Sala Plena (2006). Sentencia n ${ }^{\circ}$-071 del 3 de febrero de 2004. [Magistrado Ponente: Álvaro Tafur Galvis]

Colombia, Corte Suprema De Justicia, Sala de Casación Civil y Agraria (1992). Sentencia del 24 de junio de 1992. [Magistrado ponente: Carlos Esteban Jaramillo Schloss] Expediente nº 3390.

Colombia, Corte Suprema De Justicia, Sala de Casación Civil y Agraria (1998). Sentencia del 17 de noviembre de 1998. [Magistrado ponente: Rafael Romero Sierra] Expediente nº 5016.

Colombia, Corte Suprema De Justicia, Sala de Casación Civil y Agraria (2004). Sentencia del 19 de mayo de 2004. [Magistrado ponente: Dr. César Julio Valencia Copete] Expediente $n^{\circ}$ 7145.

Colombia, Corte Suprema De Justicia, Sala de Casación Civil y Agraria (2006). Sentencia del 4 de septiembre de 2006. [Magistrado Ponente: Edgardo Villamil Portilla] Expediente 050013103007-1997-5826-01.

Colombia, Corte Suprema De Justicia, Sala de 
Casación Civil y Agraria (2006). Sentencia del 4 de septiembre de 2006. [Magistrado Ponente: Edgardo Villamil Portilla] Expediente 050013103007-1997-5826-01

Colombia, Corte Suprema De Justicia, Sala de Casación Civil y Agraria (2009). Sentencia del 6 de mayo de 2009. [Magistrado Ponente: William Namén Vargas] Expediente 11001-3103-032-2002-00083-01

Colombia, Corte Suprema De Justicia, Sala de Casación Civil y Agraria (2019). Sentencia del 19 de marzo de 2019. [Magistrado Ponente: Octavio Augusto Tejeiro Duque] Expediente 11001310301320070061802.

Colombia, Corte Suprema de Justicia, Sala de Casación Civil y Agraria (2002). Sentencia 9 de julio de 2002. [Magistrado Ponente: José Fernando Ramírez Gómez]. Expediente 6411 Colombia, Corte Suprema de Justicia, Sala de Casación Civil y Agraria (2008). Sentencia 30 de julio de 2008. [William Namén Vargas] Expediente. 41001-3103-004-1998-00363-01

Colombia, Tribunal Superior del distrito judicial Sala de decisión civil - Familia (2011). Sentencia del 5 de abril de 2011. [Magistrado Ponente: Fernán Camilo Valencia López] Expediente 66001-31-03-005-2005-00204-01

De Castro y Bravo, F. (1967). El negocio Jurídico. Editorial Instituto Nacional de Estudios Jurídicos.

De La Morandiere, L. J. (1966) Précis de Droit Civil. Librairie Dalloz (427) 236

Ferrer Mac-Gregor, E. (2011). Interpretación conforme y control difuso de convencionalidad. Estudios Constitucionales, 9 (2), 531 - 622. http:// bit.ly/3sdvyEa

Gascón Abellán, M. (2014). ¿Lógica del descubrimiento para la prueba? García Amado, J. A. y Bonorino, P. R. (Coords.), Prueba y razonamiento probatorio en Derecho: Debates sobre abducción. $7^{a}$. ed. Editorial Comares.

Laudan, L. (2005). Por qué un estándar de prueba subjetivo y ambiguo no es un estándar. Doxa. Cuadernos de Filosofía del Derecho, (28), 95-113. https://doi.org/10.14198/DOXA2005.28.08.

Mittermaier, C. J. A. (1979) Tratado de la prueba en materia criminal, adicionada y puesta al día por Aragonés Alonso. Biblioteca jurídica de autores españoles y extranjeros E. Reus. S. A.

Orayen, R., \& Moretti, A. (2005). Filosofía de las lógicas. Editorial Trotta.

Puentes, O. E. (2019) La doctrina contemporánea sobre la prueba y su aplicación en Colombia. [Tesis de Maestría, Universidad Nacional de Colombia]. https://repositorio.unal.edu.co/ handle/unal/70424

Rocha Alvira, A. (1967). De la prueba en Derecho. Grupo Editorial Ibáñez.

Savigny, C. F. (1879). Sistema del Derecho romano actual. Universidad de Sevilla, Fondo antiguo.

Taruffo, M. (2005). Conocimiento científico y estándares de prueba judicial. Boletín Mexicano de Derecho Comparado, (114), 1285-1312. https://bit.ly/3cuUrWT

Taruffo, M. (2015). Observaciones sobre la prueba por Indicios. Tejada H. (Autor), Nuevas tendencias del derecho probatorio: Segunda edición ampliada (pp. 103-116). Universidad de los Andes, Colombia.

Vázquez, C. y Ferrer Beltrán, F. (2020) El razonamiento probatorio en el proceso judicial (1.a ed.). Editorial Marcial Pons.

Vallejo Montoya, N., Moreno Baquero, L., Arbeláez Ocampo, A., Lopera Hernández, D., Jiménez, A., Cárdenas, V., Ulloa, M., Serna, M., Posada Botero, J. D., \& Prieto Quintero, E. D. A. (2012). Aplicación del estándar de prueba por los jueces promiscuos. Universidad EAFIT. https://bit. ly/2UaKYOg

Zavaleta Rodríguez, R. E. (2018). Razonamiento probatorio a partir de indicios. Derecho \& Sociedad, (50), 197-219. https://bit.ly/31wdFF6 